\title{
Birincil ve İkincil Mineral Kaynaklarından Nadir Toprak Elementlerinin Fiziksel ve Fizikokimyasal Yöntemlerle Üretim Proseslerinin İncelenmesi
}

\author{
Esra Baştürkcü ${ }^{1 *}$, Ceyda Şavran ${ }^{1}$, İ. Servet Timur ${ }^{2}$, A. Ekrem Yüce ${ }^{1}$ \\ ${ }^{1}$ İstanbul Teknik Üniversitesi, Maden Fakültesi, Cevher Hazırlama Mühendisliği Bölümü, İstanbul, Türkiye

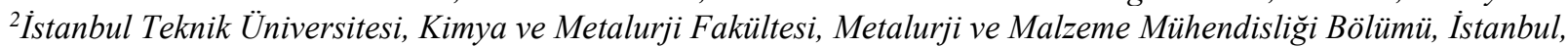 \\ Türkiye \\ *tanisali@itu.edu.tr@, savranc15@itu.edu.tr@ timur@itu.edu.tr@, yucea@itu.edu.tr@ \\ Makale gönderme tarihi: 22.03.2021, Makale kabul tarihi: 03.06.2021
}

\begin{abstract}
$\ddot{O} \mathbf{z}$
Nadir toprak elementleri (NTE), sahip olduğu özellikler sayesinde yüksek teknoloji gerektiren ürünlerde ve savunma sanayiinde kullanılmakta olup, stratejik öneme sahip olmaları ile son zamanlarda gündemdedirler. Üretim ve rezerv konusunda tekel konumda olan Çin'in ihracata getirdiği sınırlamalar ile birlikte yüksek teknoloji üreten ülkeler kaynak arayışına başlamıştır. Ticari olarak birincil NTE mineralleri bastnazit, monazit ve ksenotimdir. Bu minerallere sahip olmayan ülkeler ikincil NTE minerallerinden [Eudialyte (Ödalit), loparit, piroklor, anklisit, aegirine (egrin)] üretimleri araştırmaya ve işlemeye başlamışlardır.

$\mathrm{Bu}$ çalışma kapsamında NTE mineralleri, dünyadaki rezerv ve üretim durumu, kullanım alanları gibi genel bilgilere değinildikten sonra, birincil ve ikincil mineral kaynaklarından konsantre elde edilmesinde uygulanan yöntemler, yapılan çalışmalar ve proses akım şemaları ile ilgili bilgiler derlenmiştir.
\end{abstract}

Anahtar Kelimeler: Gravite ayırması, flotasyon, konsantrasyon, NTE, zenginleştirme yöntemleri

\section{The Investigation of Concentration Processes of Rare Earth Elements from Primary and Secondary Mineral Resources by Physical and Physico-chemical Methods}

\begin{abstract}
Rare earth elements (REE) are used in products requiring high technology and the defense industry and they have recently been on the agenda with their strategic importance. With the restrictions imposed on exports by China, which has a monopoly in terms of production and reserve, other countries producing high technology have started to search for new REE resources. Primary commercial REE minerals are bastnasite, monazite, and xenotime. Countries that do not have these mineral resources have begun to search for new sources and new processes using secondary REE minerals such as eudialyte, loparite, pyrochlore, anklicite and aegirine.

Within the scope of this study, after giving general information such as REE minerals, reserves and production status in the world, and their usage areas, information about the concentration methods from primary and secondary mineral resources, case studies, and process flow charts are compiled.
\end{abstract}

Keywords: Gravity separation, flotation,concentration, REE, enrichment methods

\section{GİRIŞ}

Nadir toprak elementleri (NTE), periyodik tablodaki 17 elementi tanımlar. Atom numaraları 57'den 71'e uzanan toplam 15 element (lantanit grubu) ve yanında 3B grubunda yer alan skandiyum ve itriyum bu gruba dahildir. Bu elementlerin "nadir" olarak nitelendirilmesi, zenginleştirme yöntemleriyle seçimli olarak birbirlerinden ayrılmalarının ve saf halde elde edilmelerinin zorluğundan kaynaklanmaktadır. Nadir toprak elementleri hafif nadir toprak elementleri (HNTE) ve ağır nadir toprak elementleri (ANTE) olarak kendi içinde iki gruba ayrılmaktadır. (Abaka-Wood vd., 2016; Suli vd., 2017; Goodenough vd., 2018). Bu elementlerin periyodik tabloda gösterimi Şekil 1'de verilmektedir. 

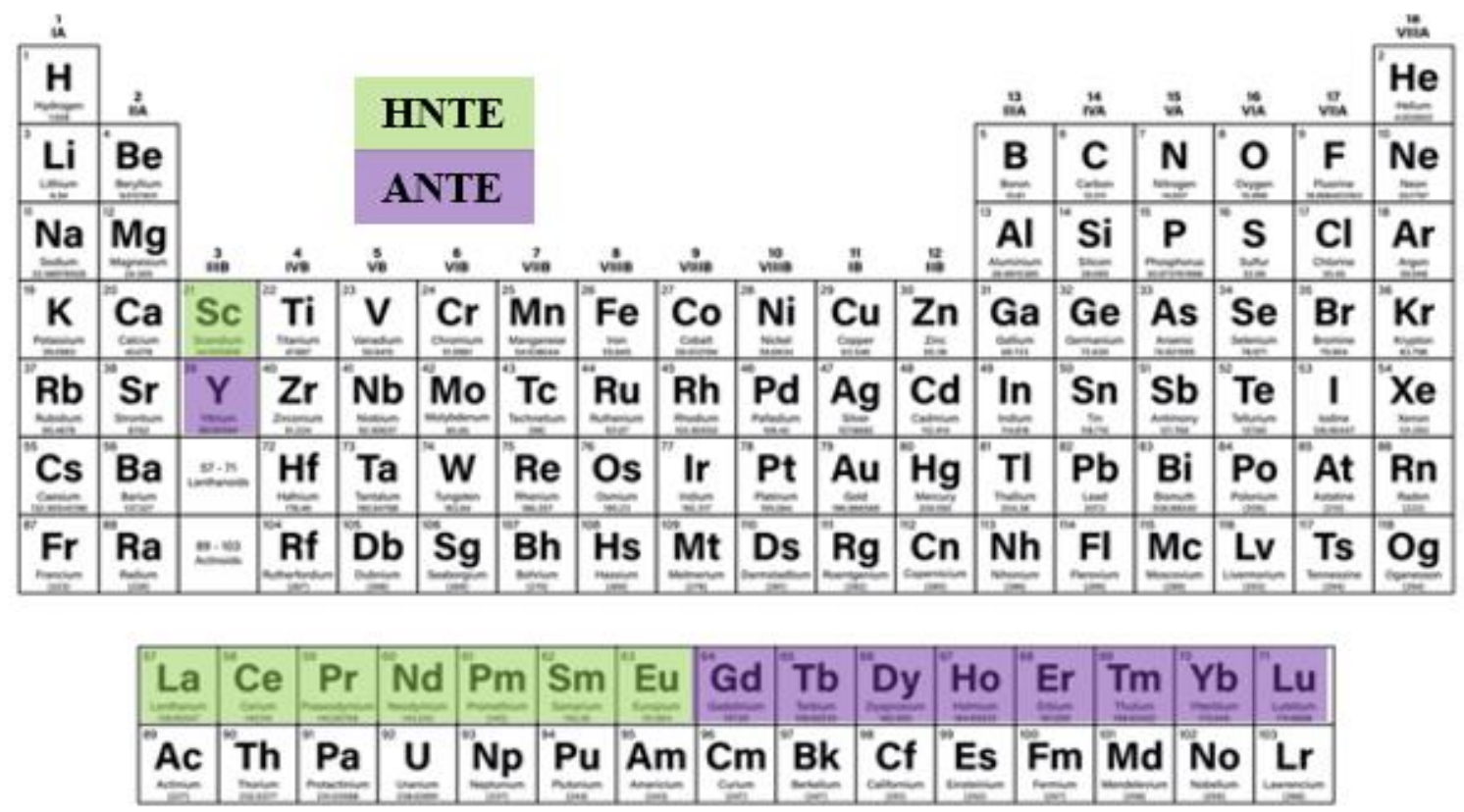

Şekil 1. Periyodik tabloda NTE'lerin gösterimi

ve zenginleştirilmesi için çeşitli kısıtlamalar

Nadir toprak metallerinin artan önemiyle beraber Çin hükümeti 2007'de nadir toprak metallerini "stratejik emtialar" olarak tanımlamıştır. NTE'lerin stratejik elementler olarak anılmasının sebeplerinden biri de savunma sanayisinde kritik rol almalarıdır. Bununla birlikte yenilenebilir enerji, hibrid araçlar, kalıcı miknatıslar ve katalizörler gibi yüksek teknoloji gerektiren alanlarda kullanılmaktadır. Çin, tedarik zinciri boyunca nadir toprak metallerinin (NTM) üretimine hakimdir. $\mathrm{Bu}$ üretim, maden üretiminin \%97'si, oksitlerin \%97'si, metal alaşımlarının \%90'1, neodyum kalıcı mıknatısların \%75'i ve samaryum kalıcı miknatısların \%60'inı oluşturmaktadır. Çin, sahip olduğu NTE rezervleri ve üretimindeki artış sayesinde tekel konumundadır ve hiçbir ülke bu sektörde Çin ile yarışabilir konumda değildir. Çin, kendi kontrolü altında NTE madenciliği başlatılmıştır. Aynı zamanda NTE için yıllık ihracat kotalarını düşürerek bazılarının ihracatını tamamen yasaklamıştır. Çin'in üretiminin yanında tüketiminin de oldukça yüksek olması, kendi taleplerinin toplamın yaklaşık \%70'ini oluşturması ile gelecekte bu talebe bağlı olarak yerli üretimin yetersiz kalabileceği gibi nedenler Çin'i NTE ithalatçısı haline getirebileceğinden, yüksek teknoloji üreten ülkelerin hem kendi ihtiyaçlarını hem de artan talepleri karşılamak amacıyla NTE üretiminin geliştirilmesi gerekmektedir (Campbell, 2014; Schüler vd., 2011; Mancheri, 2015). Tablo 1'de verilen USGS (United States Geological Survey) verilerine bakıldığında, 2019 y1lına kıyasla 2020 y1lında Dünya'da üretilen nadir toprak oksitlerinin miktarları yaklaşık 20 bin ton artmıştır. Bu üretimi yapan ülkelerin başında Çin gelmektedir

Tablo 1. NTE maden üretiminin Ülkelere göre dağılımı (USGS, 2021)

\begin{tabular}{lll}
\hline Ülkeler & \multicolumn{2}{l}{ Maden üretimi ( ton) } \\
& $\mathbf{2 0 1 9}$ & $\mathbf{2 0 2 0}$ \\
\hline Çin & 132.000 & 140.000 \\
\hline ABD & 28.000 & 38.000 \\
\hline Myanmar (Burma) & 25.000 & 30.000 \\
\hline
\end{tabular}




\begin{tabular}{lll}
\hline Avustralya & 20.000 & 17.000 \\
\hline Madagaskar & 4.000 & 8.000 \\
\hline Hindistan & 2.900 & 3.000 \\
\hline Rusya & 2.700 & 2.700 \\
\hline Tayland & 1.900 & 2.000 \\
\hline Vietnam & 1.300 & 1.000 \\
\hline Brezilya & 710 & 1.000 \\
\hline Burundi & 200 & 500 \\
\hline Diğer ülkeler & 66 & 100 \\
\hline
\end{tabular}

Üretimin yanında en yüksek tüketim yapan ülkelerin başında da Çin gelmektedir. Çin'i Japonya, ABD, Almanya ve Fransa takip etmektedir. 2015 y1l itibariyle NTE ihracatının \%35'i ABD, \%23,4'ü Brezilya, \%9,5'i Çin, \%8,5'i Avrupa Birliği, \%8,3'ü Belçika'ya ve diğer ülkelere aittir. Toplam yapılan ihracat miktarı ise 7.660 tondur. 2015 yılından itibaren ithalat durumlarına bakıldığında ise toplam 5.149 ton NTE ithalat1, \%18 Singapur, \%17,7 Malezya, \%12 Çin, \%6,4 Avrupa Birliği \%4 ABD, $\% 4$ ile Almanya'ya aittir (MTA, 2017).

Dünyadaki en büyük rezervlere sahip olan ülke Çin'dir. 2021 USGS verilerine göre dünya nadir toprak rezervleri yaklaşık 120 milyon tondur. NTE rezervleri ülkelere göre en yüksek rezerv \%39 dilim ile Çin ve takiben \%19 oranları ile Vietnam ve Brezilya gelmektedir (Șekil 2).

Kaynakların kısıtlılığı ve ticari savaşlar göz önünde bulundurulduğunda birincil kaynaklara sahip olmayan ve yüksek teknoloji üreten ülkeler alternatif kaynaklara yönelmektedir. Bu ikincil kaynaklar, endüstriyel artıklar; e-atık (hard diskler, floresan lambalar, NdFeB magnetler, vb.) ile maden artıkları; yan ürünler, kömür, kömür yıkama artıkları, termik santral taban ve uçucu külüdür (Zhang vd., 2020; Jyothi vd. 2020). Bu artıklardan NTE kazanımı ile hem çevresel sorunlara çözüm bulunmakta hem de doğal kaynakların korunması ve NTE rezervine sahip olmayan ülkeler için alternatif oluşturulması sağlanmaktadır (Costis vd., 2021)

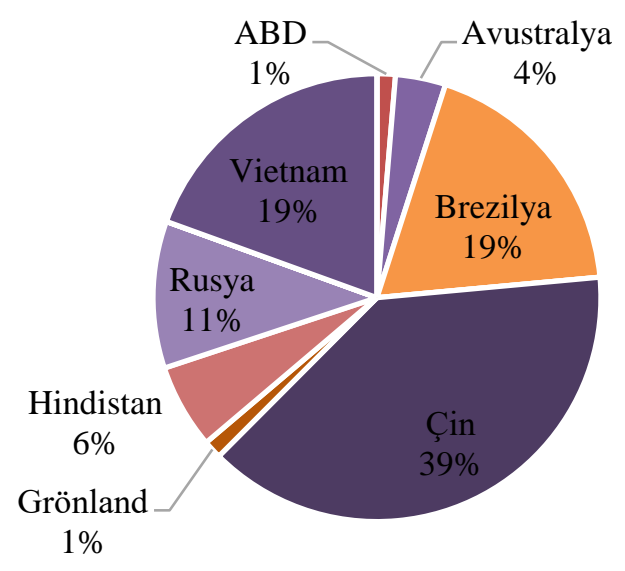

Şekil 2. Dünya NTE rezerv dağılımı (USGS, 2021)

Nadir toprak elementlerinin temel olarak 4 farklı yatak oluşumundan söz edilmektedir. $\mathrm{Bu}$ yatak türleri: karbonatit, alkali-volkanik, iyon adsorpsiyon killer ve plaser yatak olarak sınıflandırılabilmektedir. HNTE grubu mineraller karbonatit ve plaser tipli yataklarda yoğunlaşırken, alkali-volkanik kayaçlar ve iyon adsorpsiyon killerinde ağır NTE grubu mevcuttur (Dostal, 2017). Bu mineraller fosfat, karbonat, oksit ve silikat formlarında bulunabilmektedir. Nadir toprak elementlerinin 250 'den fazla mineral yapısında yer aldığ bilinmektedir (Gupta \& Krishnamurthy, 2005). Mineral oluşumuna göre HNTE bir diğer adı ile Seryum grubu, loparit, bastnazit, parisit, monazit, eshipit ve ortit minerallerinde bulunurken, ANTE/ itriyum grubu elementler; itriyoparisit, samarskit, priyorit, ksenotim, gadolint gibi minerellarde yer alabilmektedir (Bulatovic, 2010).

Dünya'da ticari üretimin \%95'i bastnazit, monazit ve ksenotim minerallerinden gerçekleştirilmektedir. Ticari olarak üretim yapılan maden yatakları ülke ve firma bilgileri Tablo 2'de verilmektedir. Ticari mineraller ile birlikte önemli 
sayılan ve üretim olanakları araştırılan diğer mineraller Tablo 3'de kimyasal bileşim, NTO (Nadir toprak oksit) içeriği ve cevher tipine göre gösterilmektedir.

Dünyadaki tüm yataklar göz önüne alındığında, 1927'de demir rezervi olarak keşfedilen ve
Moğolistan'da bulunan Bayan Obo yatağı, şu anda bilinen en büyük nadir toprak yataklanmasıdır. İkinci en büyük yatak ise Kaliforniya'da bulunan ve 1952'de işletmeye alınan Mountain Pass yatağıdır (Dushyanthaa vd., 2020).

Tablo 2. Dünya'da NTE üretimi yapılan sahalara ilişkin bilgiler (Dushyanthaa vd., 2020)

\begin{tabular}{lll}
\hline Firma & Ülke & Maden Yatağı \\
\hline Molycorp, Inc. & ABD & Mountain Pass \\
\hline Lynas Ltd. & Avustralya & Mount Weld \\
\hline Avalon Rare Metals, Inc. & Kanada & Nechalacho (Thor Lake) \\
\hline Alkaline Resources & Avustralya & Dubbo \\
\hline Arafura Resources, Ltd. & Avustralya & Nolans Bore \\
\hline Rare Element Resources, Ltd. & ABD & Bear Lodge (Bull Hill Zone) \\
\hline Great Western Minerals Group, Ltd. & Kanada & Steenkampskraal \\
\hline Greenland Minerals and Energy, Ltd. & Avustralya & Kvanefjeld \\
\hline Quest Rare Minerals, Ltd. & Kanada & Strange Lake (B zone) \\
\hline Tasman Metals, Ltd. & Kanada & Norra Karr \\
\hline Stans Energy Corp. & Kanada & Kutessay II \\
\hline Ucore Rare Metals, Inc. & Kanada & Bokan (Dotson) \\
\hline
\end{tabular}

Tablo 3. Önemli NTE mineralleri (MTA, 2017)

\begin{tabular}{|c|c|c|c|}
\hline Mineral Adı & Kimyasal Bileşimi & Cevher Tipi & NTO, \% \\
\hline Allanit & $(\mathrm{Ca}, \mathrm{NTE}, \mathrm{Th})_{2}(\mathrm{Al}, \mathrm{Fe}, \mathrm{Mg})_{3} \mathrm{Si}_{3} \mathrm{O}_{12}(\mathrm{OH})$ & Silikat & 28 \\
\hline Apatit & $\mathrm{Ca}_{5}\left(\mathrm{PO}_{4}\right)_{3} \mathrm{~F}$ & Fosfat & 12 \\
\hline Bastnazit & $(\mathrm{Ce}, \mathrm{La}) \mathrm{FCO}_{3}$ & Fluorokarbonat & 75 \\
\hline Brannerit & $(\mathrm{U}, \mathrm{Ca}, \mathrm{Fe}, \mathrm{Th}, \mathrm{Y})_{3} \mathrm{Ti}_{5} \mathrm{O}_{16}$ & Oksit & 12 \\
\hline Serit & $\mathrm{CaCe} 6 \mathrm{Si}_{3} \mathrm{O}_{13}$ & Silikat & 70 \\
\hline Öksenit & $(\mathrm{Y}, \mathrm{Ca}, \mathrm{Ce}, \mathrm{U}, \mathrm{T})(\mathrm{Nb}, \mathrm{Ta}, \mathrm{Ti})_{2} \mathrm{O}_{6}$ & Oksit & 12 \\
\hline Fergusonit & $(\mathrm{Y}, \mathrm{Sr}, \mathrm{Ce}, \mathrm{U})(\mathrm{Nb}, \mathrm{Ta})_{2} \mathrm{O}_{2}$ & Oksit & 46 \\
\hline Gadolinit & $\mathrm{Be}_{2} \mathrm{FeY}_{2} \mathrm{Si}_{2} \mathrm{O}_{10}$ & Silikat & 48 \\
\hline Fluoserit & $\mathrm{CeF}_{3}$ & Fluorür & 70 \\
\hline Piroklor & $(\mathrm{Na}, \mathrm{Ca}, \mathrm{Ce})_{2} \mathrm{Nb}_{2} \mathrm{O}_{6} \mathrm{~F}$ & Oksit & 6 \\
\hline Samarskit & $(\mathrm{Y}, \mathrm{Ce}, \mathrm{U}, \mathrm{Ca})(\mathrm{Nb}, \mathrm{Ta}, \mathrm{Ti})_{2} \mathrm{O}_{6}$ & Oksit & 22 \\
\hline Ksenotim & $\mathrm{YPO}_{4}$ & Fosfat & 62 \\
\hline Monazit & $(\mathrm{Ce}, \mathrm{La}, \mathrm{Th}, \mathrm{Y}) \mathrm{PO}_{4}$ & Fosfat & 65 \\
\hline Zirkon & $(\mathrm{Zr}, \mathrm{Th}, \mathrm{Y}, \mathrm{Ce}) \mathrm{SiO}_{4}$ & Silikat & --- \\
\hline
\end{tabular}

Nadir toprak elementlerinin kullanımına bakılacak olursa; 1890'lı yıllarda başlayan ve teknolojinin de ilerlemesi ile artarak devam eden trend göze çarpmaktadır. NTE'lerin yüksek elektrik iletkenliği, güçlü manyetizma ve yüksek parlaklık gibi benzersiz fiziksel ve kimyasal özellikleri bu elementleri vazgeçilmez bir konuma taşımıştır (Dushyanthaa vd., 2020). Nadir toprakların bilinen en önemli kullanım alanları katalizörler, nadir toprak mıknatısları, alaşımlar, toz üretimi ve fosforlardır. 
Hem endüstriyel hem oto katalizörler olarak kullanılan katalizörler için genellikle lantan (La) ve seryum (Ce) kullanılır. Bu iki elementin diğer NTE'lere göre daha ucuz olmasindan dolayı cam, cilalama, seramik gibi uygulamalarda da kullanımı yaygındır. Fosforlar için daha pahalı olan evropiyum $(\mathrm{Eu})$ ve terbiyum $(\mathrm{Tb})$ kullanilırken, magnetlerde ise neodyum (Nd), praseodim (Pd), disporsiyum (Dy) ve terbiyum (Tb) kullanılmaktadır (Haque vd., 2014; Schüler vd., 2011; Dushyanthaa vd., 2020).

NTE'lerin en önemli kullanım alanlarından biri olan temiz teknoloji kapsamında yer alan ve yenilenebilir enerjinin en önemli kaynakları olan güneş panelleri ve rüzgar türbinleri için NTE'ler anahtar rol oynamaktadır. Güneş panellerinde güç dönüşüm verimliliğini artırmak amacıyla $\mathrm{Pr}, \mathrm{Gd}, \mathrm{Eu}$ ve Er elementleri nanopartikül bazlı malzemeler olarak kullanılır. Rüzgar türbinlerinde, rüzgar enerjisini elektriğe dönüştürmek için kalıcı mıknatıs jeneratörlerine ihtiyaç vardır ve bu jeneratörler içerisinde bulunan NTE'ler Nd, Tb ve Dy'dir. Hibrid elektrikli araçlarda, araçların bataryasında depolanan enerjiyi mekanik güce dönüştürmek amacıyla da NTE'ler kullanılmaktadır. NTE'lerin stratejik elementler olarak anılmasının nedenlerinden biri de askeri uygulamalarda kritik rol almalarıdır. Örneğin; samaryum kobalt ( $\mathrm{SmCo}$ ) ve neodyum demir bor (NdFeB) mıknatıslar gibi kalıcı mıknatıslar, füzeler, akıllı bombalar, saldırı cephaneleri, insansız uçaklar gibi birçok savunma uygulamasında yüksek oranda kullanılmaktadır. (Suli vd., 2017; Dushyanthaa vd., 2020; Abaka-Wood vd., 2016).

Nadir toprak elementlerinin birincil kaynaklardan konsantre üretim proseslerinde birçok parametre göz önünde bulundurulmalıdır. Zenginleştirme işlemlerinde seçilecek olan yöntemlere karar verilirken en temel unsurlar NTE mineral tipi, tane serbestleşme boyutu ve gang mineralleridir. NTE'ler oksit, fosfat, silikat, karbonat gibi farklı formlarda cevherleşmekte ve her bir tür farklı tip yataklarda oluşmaktadır. Bu yataklarda oluşan NTE minerali aynı olsa bile cevherleşme çok farklı olmakta, yan kayaçlar ve tane serbestleşmesi çeşitlilik göstermektedir. Dolayısı ile keşfedilen ve işletilen her bir saha için uygulanacak yöntem ve proses akım şeması farklılık göstermektedir. Örneğin; Karbonatit sahas1 olan Bayan Obo ve Mountain Pass'te temel mineral bastnazit iken Bear Lodge sahasında ankilit NTE mineralidir. Bir başka karbonatit sahası Songwe Hill'de NTE sinçesit ve apatit ile birlikte bulunmaktadır (Goodenough et al., 2017).

Zenginleştirme işlemlerinde özgül ağırlık farkından faydalanarak ayırma, elektrostatik ayırma, manyetik ayırma ve flotasyon yöntemleri kullanılabilmektedir (Jorden vd., 2013). Bu makale kapsamında ticari olarak üretimi yapılan birincil (bastnazit, monazit, ksenotim) ve ikincil (ödalit, loparit, piroklor, anklisit, fergusonit, egrin) NTE minerallerinin fiziksel ve fizikokimyasal zenginleştirme prosesleri güncel bir literatür derlemesi olarak sunulmaktadır.

\section{BİRINCIL NTE MINNERALLERINDEN KONSANTRE ÜRETIMI Bastnazit}

Bastnazit, bir florokarbonat mineralidir ve nadir toprak oksit içeriği yaklaşık \% 70'dir. Bunun ortalama \%97'si Ce, La, Pr ve Nd'dir. Bastnazit genellikle karbonatlı silikat kayaçlarında izlenir. Bastnazit daha çok kalsit, barit, florit veya demir mineralleriyle bileşik halinde bulunmaktadır. Hem bastnazitin hem de yan kayacın kimyasal bileşimleri uygulanacak zenginleştirme yöntemini belirlemektedir. Bastnazitin zenginleştirilmesinde en çok tercih edilen yöntem ise flotasyondur (Y1ldı, 2016; Jordens vd., 2013).

Türkiye'de Eskișehir- Beylikova Bölgesi'nde kompleks yapıda, 1 milyon tonluk, ortalama \%3.42 NTO içerikli bir rezerv olup, NTE, barit, florit ve toryumla beraber bulunmaktadır. Bastnazit, bu bölgenin ana nadir toprak mineralidir. Özbayoğlu ve Atalay (2000), yaptıkları çalışmada bu bölgeden aldıkları cevheri kullanmışlardır. $1.65 \mathrm{~mm}$ altına kırılmış cevhere mekanik dağıtma uygulanmış, dağıtmayı takiben siklon ile ayırma yapılmış ve üst akımından \%28 NTO içerikli ön konsantre niteliğinde bir şlam \%72.6 verimle ayrılmıştır. Elde edilen ön konsantre, içeriği yükseltilmek amacıyla Mozley multi-gravite ayırıcısına (MGS) verilmiştir. $\mathrm{Bu}$ zenginleştirme işlemi sonucunda bastnazit ön konsantresi \%35.5 NTO içeriği ve \%48 verimle üretilmiştir. Ön konsantrenin kimyasal içeriklerine bakıldı ̆̆ında $\% 13.75 \mathrm{Ce}, \% 11.81 \mathrm{La}, \% 2.30 \mathrm{Nd}, \% 1$ Pr içermektedir. Ön konsantreye asit kavurması ve su liçi uygulamasıyla, \%73-80 arası verimle NTE kazanımı gerçekleşmiş̧ir.

$\% 6$ tenörlü 48 milyon ton rezervle dünyanın en büyük rezervi olarak bilinen Bayan Obo, hidrotermal kaynaklı 71 element ve 170 mineralden oluşan 
kompleks bir polimetalik yataktır ve NTE, Nd ve Fe üretimi yapılmaktadır. 1927'de Fe madeni olarak keşfedilmiş, 1990'larda NTE üretimine başlanmıştır. Yatak yüksek tenörlü olmasına rağmen, nadir toprak elementleri yalnızca demir cevheri madenciliği ve zenginleştirme işlemlerinin yan ürünü olarak kazanılmaktadır. NTE'lerin \%90'1 serbest olarak florit ve Fe mineralleri içerisinde yer almaktadır. 15 farklı NTE minerali bulunmasına karşın baskın olanlar basnazit ve monazittir. Bununla birlikte birçok oksitli $\mathrm{Nd}$ minerali bulunmaktadır. Başlıca gang mineralleri ise kuvars, apatit, dolomit ve florittir. Bu yatakta bulunan NTE minerellerinin çoğu ince tanelidir ve serbestleşme boyutu 74 ile 10 mikron arasında değişmektedir. Bundan dolayı NTE kazanımı oldukça zorlaşmaktadır (Faris vd., 2017; Li \& Yang, 2014). 1950'lerden 1990'a kadar 20'ye yakın proses denenmiştir. 1990'da Changsha Metalurjik araştırma enstitüsü tarafından bugün kullanılan proses akım şeması geliştirilmiştir. 74

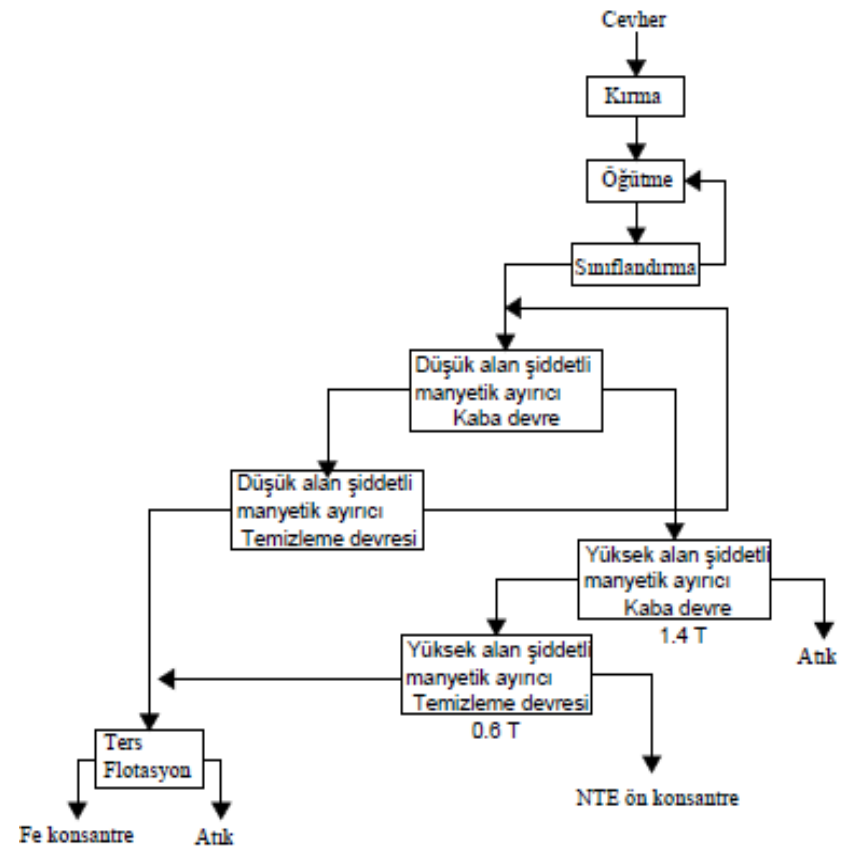

mikron altına öğütülen numune de, öncelikle düşük alan şiddetli manyetik ayırıcı (D.A.Ş.M.A.) ile manyetit zenginleştirilir. Artık numune yüksek alan şiddetli manyetik ayırıcı (Y.A.Ş.M.A.), manyetik alan şiddeti:1.4 T, ile zenginleştirilerek hematit ve NTE minerallerinin büyük çoğunluğu konsantrede kazanılır. Bir kademe daha yüksek alan şiddetli manyetik ayırma ile (manyetik alan şiddeti:0.6 T) temizleme kademesi uygulanir. Temizleme kademesinde hematit konsantrede alınırken NTE mineralleri artıkta kalmaktadır. Artıkta konsantre olan NTE minerelleri zenginleştirilmek üzere flotasyon işlemine tabii tutulur. Düşük ve yüksek alan şiddetli Manyetik ayırıcıda zenginleştirme ile elde edilen konsantreler birleştirilerek Fe içeriğindeki safsızlıkların temizlenmesine yönelik ters flotasyon uygulanarak nihai Fe konsantresi elde edilir ( $\mathrm{Li}$ ve Yang, 2014). Bayan Obo'nun basitleştirilmiş akım şeması Şekil 3'de verilmektedir.

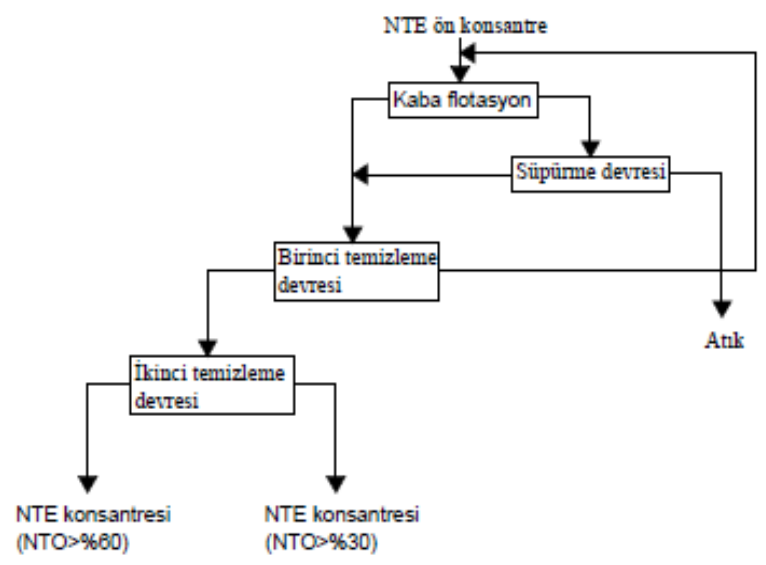

Şekil 3. Bayan Obo basitleştirilmiş proses akım şeması (Li ve Yang, 2014)

NTE flotasyonunda 1970'den 1990'a kadar birçok reaktif denenmiştir. İlk olarak yağ asidi türevi olan oleik asit kullanılırken, daha sonra $\mathrm{C}_{5-9}$ hidroksamik asit kullanılmıştır. 1980’lerde naptenik asitten üretilen cyclic alkil hidroksamat kullanılmaya başlanmış ve \%50-60 NTO konsantresi elde edilmiştir. İlerleyen yıllarda cyclic alkil ve alkil hidroksamatların seçiciliğinin düşük olması nedeniyle aromatik hidroksamik asit olan $\mathrm{H}_{205}$ olarak adlandırılan reaktif geliştirilmiştir. Bulunan bu yeni reaktifle birlikte aktivatör olarak kullanılan NaF'e bile gerek duyulmamıştır. 1990'lardan sonra $\mathrm{H}_{205}$ 'den üretilen "No.8 flotasyon yağı" adı ile çift yönlü hidroksamik asit grubuna sahip reaktif geliştirilmiş 
olup flotasyon devresinde kullanılmaktadır ( $\mathrm{Li}$ ve Yang, 2014).

Dünyadaki ikinci en büyük NTE yatağ 1 , Kaliforniya'da bulunan ve MolyCorp tarafindan işletilen Mountain Pass madenidir. 1960'larda işletilmeye başlayan yatağın NTO tenörü \%6-12 arasındadır. İşletmenin y1llık kapasitesinin 15.000 ton olduğu bilinmektedir. $\mathrm{Bu}$ yatak, seryum grubu NTE'ler bakımından zengindir ve ağırlıklı olarak bastnazit ve monazit bulunmaktadır. Gang mineralleri arasında barit, kalsit, silikat, apatit, dolomit sayılmaktadır. Tesiste kullanılan zenginleştirme yöntemi flotasyondur (Yang vd., 2015; Y1ld1z, 2016; Abaka-Wood vd., 2016). Bastnazit cevheri, flotasyona girmeden önce \%80'i $45 \mu \mathrm{m}$ altında olacak şekilde ögütülür. Flotasyon devresine giren pülp, dört aşamalı kondüsyonlanmadan geçer ve bu aşamalarda sıcaklık $82{ }^{\circ} \mathrm{C}$ 'de tutulmaktadır. İlk aşamada $\mathrm{pH}$ ayarlayıcı olarak kullanılan soda külü aynı zamanda gang minerallerini (barit, kalsit) bastırıcı etki gösterir. İkinci aşamada herhangi bir kimyasal eklemesi yapılmamaktadır. $\mathrm{pH}$ ve bastırıc etkisinin tamamlanması beklenmektedir. Üçüncü aşamada gang minerallerini bastırmak amacıyla lignin sülfonat eklenmektedir. Dördüncü ve son aşamada ise toplayıc1 olarak yağ asidi ilavesi yapılmaktadır. Kondisyonlanma sonrası pülpün, pülpte katı oranı $\% 40$ 'tır ve üç aşamalı kaba flotasyon devresine verilmektedir. Kaba konsantre, dört aşamalı temizleme devresine gönderilmekte ve elde edilen konsantre \%60-70 arasında NTO içeriğinde, \%60-70 verimle elde edilmektedir (Anderson vd., 2016).

\section{Monazit}

Monazit, NTE üretiminin en çok yapıldığı ikinci kaynak olup genellikle sahil kumlarından zenginleştirilmektedir. Ayrıca granitler ve metamorfik kayaçlara bağlı minerallerde de oluşabilmektedir. Avustralya, Brezilya, Çin, Hindistan, Malezya, Güney Afrika, Sri Lanka, Tayland ve Amerika'da monazite rezervleri mevcuttur (Wall, 2014).

Karbonatit tip yataklarda baskın mineral genellikle bastnazit ve florakarbonatl yapılar olmakla birlikte ikincil baskın NTE minerali monazittir. Dünyadaki iki büyük örneği Bayan Obo ve Mountain Pass'dir. Ülkemizde bulunan
Kızılcaören cevheri bu yatak tipine bir örnektir. Monazitin baskın bulunduğu bir diğer yatak tipi ise oksidasyon-sedimentasyon yatağıdır. Mount Weld ve Araxa bu yatak tipinin örneklerindendir (Chen vd., 2017). Sahil kumlarında bulunan monazitlerde karbonatit tip yataklara oranla daha yüksek Th ve U içeriği tespit edilmiştir (Dushyantha vd., 2020).

Monazit, genellikle rutil,ilmenit ve zirkon ile birarada sahil kumlarında yer alır. Mineral \%10-40 $\mathrm{La}_{2} \mathrm{O}_{3}, \% 4-12 \mathrm{ThO}_{2}, \% 20-30 \mathrm{Ce}_{2} \mathrm{O}_{3}$ ve yüksek miktarda Nd, Pr ve Sm içermektedir (Gupta ve Krishnamurthy, 2005).

Mount Weld yatağ 1,2011 yılında işletmeye alınmıştır. Yaklaşık 2 milyon ton rezervi olan yataktan y1llı 26.5 ton NTO konsantresi elde edilmektedir (Lynas Rare Earth, t.y.). Monazitin büyük çoğunluğu ince boyutta (25 mikron altı) serbestleşebilen kompleks bir cevherdir. Monazit ile birlikte bulunan gang mineraller, demir oksitler, fosfatlar ve killerdir. Flotasyon ile zenginleștirmenin uygulandığ 1 bu proseste, flotasyon öncesinde şlam atılmakta olup, şlam boyutu NTE kaybı açısından önem taşımaktadır. Yapılan çalışmalarla 4 mikron altı şlamda NTE kaybı minimum olarak elde edilmiştir. Cevherin \%80'i 65 mikron altına öğütüldükten ve şlamı uzaklaştırıldıktan sonra temizleme ve süpürme kademelerinin uygulandığ 1 flotasyon zenginleştirmesiyle nihai konsantre $\% 58.5$ içerik ve $\% 77.5$ verim ile elde edilmektedir. Köpürtücü olarak hidrokarbon yağı ile modifiye edilen yağ asiti ve monaziti canlandırmada $\mathrm{Na}_{2} \mathrm{~S}$ kullanılmaktadır. (Bulatovic, 2010).

Plaser yataklarda, monazitle birlikte bulunan başlica mineraller ilmenit, zirkon, rutil ve kuvarstır. Manavalakurichi, Pulmoddai yatağı, Orissa ve Chavara ile Hindistandaki Aluva'da monazit bulunmaktadır (Gupta ve Krishnamurthy, 2005). Ayrıca Malezya, Güney Afrika, Hindistan'daki Kerala, Andhra Pradesh, Tamil Nadu ve Odisha yatakları da sahil kumlarındaki monazit yataklarına örnektir. Çin, Malezya ve Hindistan monazit üretiminde etkinliği ile bilinirken bu ülkeler dıșında Brazilya ve Rusya da monazit üretimine giriş yapmış durumdadır (Balaram, 2019)

Sahil kumlarındaki zenginleştirme işlemi temel olarak gravite ile ayırma, manyetik ayırma ve elektrostatik ayırma işlemlerini kapsamaktadır. $\mathrm{Bu}$ 
yöntemler, minerolojiye ve serbestleșme tane boyutuna bağlı olarak farklı kombinasyonlarla uygulanabilmektedir. Öncelikle gravite ayırma ile kuvars gibi yoğunluğu düşük mineraller ağır minerallerden ayrılmaktadır. Bu ayırma işlemlerinde sarsintılı masa, spiral ile daha ince boyutta serbestleşen mineraller için knelson, falcon gibi santrifüjlü gravite ayırıcıları kullanılmaktadır. Gravite ayırmasında ilmenit, rutil, zirkon ve monazit ağır fraksiyonda yoğunlaşmaktadır. Elektrostatik iletkenliği olan ilmenit ve rutil ile yalıtkan olan monazit ve zirkon birbirinden ayrılmaktadır. Monazit paramanyetik bir mineral olup diamanyetik olan zirkondan yüksek alan şiddetli manyetik ayırıcı yardımı ile ayrılabilmektedir. (Jordans vd., 2013 ; Kumari, vd. 2015; Terzi, 2017).

Misır sahil kumlarında \%30 oranda ağır mineraller (monazit, rutil, zirkon,ilmenit) mevcuttur. Moustafa ve Abdelfattah (2010) tarafindan yapılmış olan çalışmada gravite ayırması ile kuvars uzaklaştırıldıktan sonra, manyetik ayırma ve elektrostatik ayırma yöntemlerini içeren çok kademeli proses akım şeması ile ağır mineraller seçimli olarak elde edilmiştir (Moustafa ve Abdelfattah, 2010).

\section{Ksenotim}

Ksenotim esas olarak \%54-65 NTO içeren bir itriyum fosfat $\left(\mathrm{YPO}_{4}\right)$ mineralidir. Ağırlıklı olarak ANTE (Y), toryum ve uranyum içerir. Genellikle ağır mineral kumların, pegmatitin ve magmatik kayaların bir bileşenidir. Ksenotim, monazite benzer bir oluşum sürecinden geçmiştir ve plaser yataklarda monazitle beraber bulunur. Bu tür yataklardaki ksenotim içeriği, monazitin yaklaşık \%0.5-5'i kadar olmaktadır. Malezya'daki plaser kasiterit yataklarında, Avustralya ağır mineral kumlarının bazılarında,
Brezilya'daki alüvyon kalay madenlerinde ksenotim bulunduğu bilinmektedir. NTE taşıyan kayaçların erozyon süreci, monazit, ksenotim, ilmenit ve rutil gibi ağır mineralleri birarada yoğunlaştırmıştır (Gupta ve Krishnamurthy, 2005; Dushyantha vd., 2020). Rutil ve ilmenit dişında plaser ve sahil kumlarında manyetit, zirkon ve kasiterit de bulunmaktadır. Monazit ile ksenotim diğer minerallerin kazanılmasında yan ürün olarak elde edilmektedir. Monazit ve ksenotim mineralleri, yüksek özgül ağırlık ve kimyasal olarak tepkimeye girmemeleri ile ayırt edilebilmektedir. Elektrostatik ayırma sırasında ilmenit ve rutil iletken özellik göstermektedir. Manyetik özelliklerine göre sıralandığında en yüksek manyetik duyarlılığ 1 ilmenit gösterirken diğer mineraller garnet, ksenotim, monazit şeklinde devam eder. Ksenotim, monazite göre çok daha yüksek manyetik özellik gösterdiğinden, manyetik ayırma sırasında ilmenit ile beraber alınır. Daha sonra ksenotim ve ilmeniti ayırmak için ise elektrostatik yöntem tercih edilmektedir (Y1ldız, 2016; Gupta ve Krishnamurthy, 2005). Şekil 4'de sahil kumlarından monazit ve ksenotim eldesine yönelik oluşturulan proses akım şemas1 verilmektedir.

Çin'deki rutil cevheri numunesi üzerinde ön zenginleştirme uygulanmıştır. $\mathrm{Bu}$ işlem sonucunda ksenotim ön konsantresi elde edilerek deneylerde kullanmıştır. Zhang (2016), yaptığı çalışmada, birçok kollektör denemesine karşın, en verimli olan kollektör oktano hidroksamik asit olmuştur. Ksenotimin diğer gang minerallerinden ayrılabildiği en uygun $\mathrm{pH}$ 9'dur. Bastırıcı olarak sodyum silikat ve amonyum lignosülfatın, oktano hidroksamik asit ile, $80{ }^{\circ} \mathrm{C}$ 'de verimli çalıştığını gözlemlenmiştir. Ancak bu bastırıcıların ilmenitin bastırılması üzerinde etkisi olmamıştır. Bu iki bastırıcının da, oda sıcaklığında ve sodyum oleat varlığında etkili olduğunu belirtmiştir. 


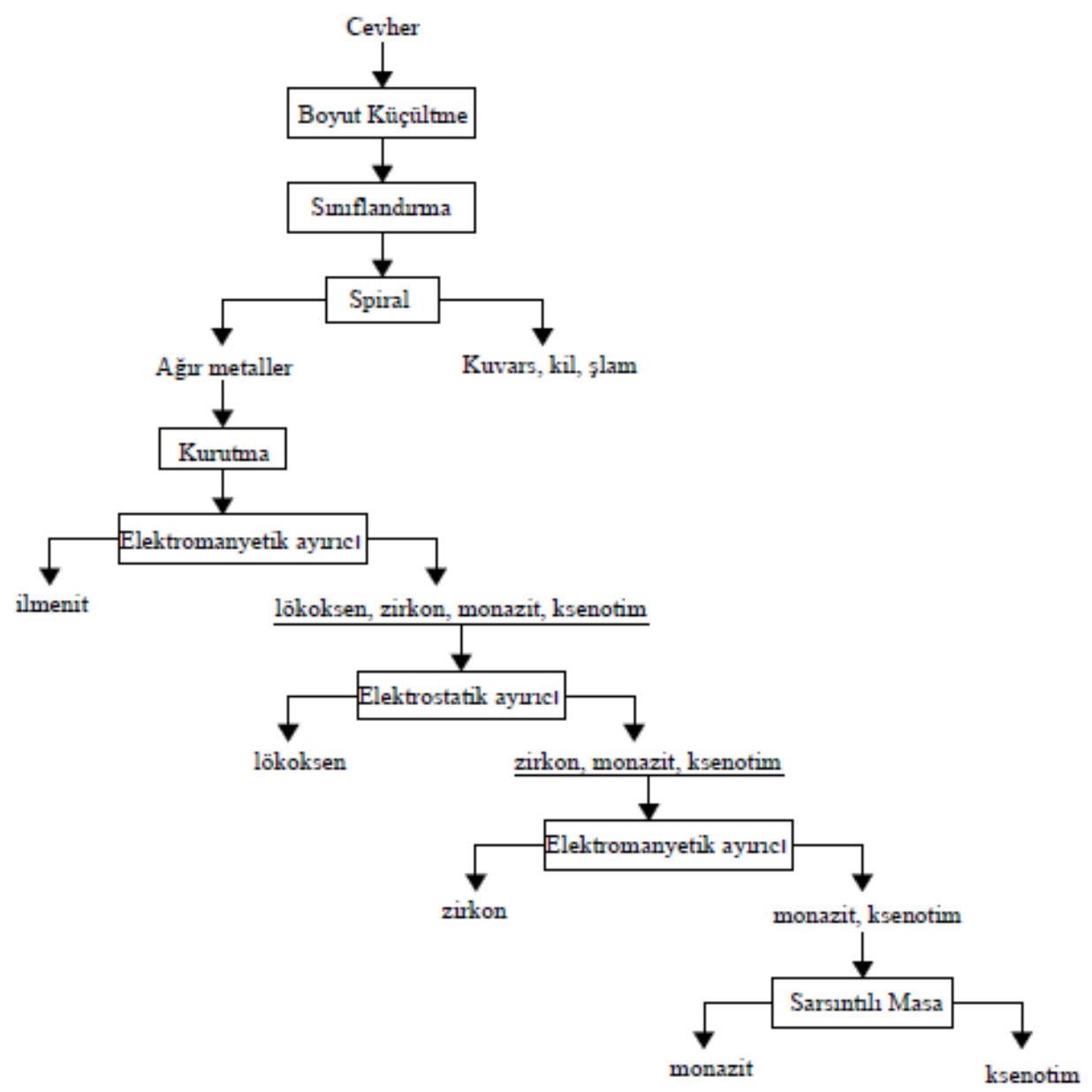

Şekil 4. Sahil kumlarından monazit ve ksenotim kazanımı (Yıldız,2016)

\section{İKINCIL NTE MINNERALLERINNDEN KONSANTRE ÜRETIMI}

Ülkemizde Eskișehir- Beylikova haricinde, Malatya Kuluncak Bölgesinde silikatlı NTE cevheri olan \%24 tenörlü 1000 ton Britolit cevherleşmesi ön görülmektedir (MTA, 2017). Bununla birlikte Isparta civarındaki bir sahada NTE minerali olarak ortalama 725 ppm içerikli Allanit, Çevkinit ve Sfen bulunduğu tespit edilmiştir. NTE'lere ek olarak manyetit, zirkon, titanyum, skandiyum, niobyum, uranyum ve toryum diğer potansiyel yan ürünlerdir (Terzi, 2017). Allanit flotasyonu ile ilgili detaylı yüzey kimyası ve mikro flotasyon çalışmaları ile literatüre katkıda bulunulmuştur (Kurşun vd., 2019)

Amerika'daki Bear Lodge Projesinde cevher ortalama \%4.5 tenörlü Anklisit (NTE minerali) ve yan kayaç olarak kalsit, demir oksitler ve strontiyanit minerallerinden oluşmaktadır. Nihai zenginleştirme yöntemi olarak flotasyon uygulanan proses akım şemasında flotasyon verimini arttırmak için kaba zenginleştirme olarak manyetik ayırma uygulanmıştır. Uygulanan manyetik ayırma ile demir oksitler ayrılmıştır. Nihai konsantre \% 11.2 NTE oksit ve \% 61.2 verimle zenginleştirilmiştir (Hao ve Corby, 2017).

İsveç sınırında bulunan Norra Karr yatağında bilinen ticari minerallerden farklı olarak Ödalit grup minerali işletilmektedir. Ödalit, Y ve diğer NTE kaynağı potansiyel bir kaynak olarak bilinmekle birlikte düşük $U$ ve Th içeriği avantaj sağlamaktadır. Nefelinli siyenit yapısında yer alan Ödalit grubu ile birlikte zirkon da yapıda zengin içeriklerde bulunmaktadır. Norra Karr ile ilgili Almanya Aachen Üniversitesi tarafından yürütülen çalışmada ön 
zenginleștirme olarak manyetik ayırma denenmiştir. Yüksek alan şiddetli kuru ve yaş manyetik ayırıcıları kullanılarak gang minerallerinin tek adımda ödalitden ayrılması amaçlanmıştır. Ancak gang minerali olan egrin ve ödalit'in manyetik duyarlılıkları birbirlerine çok yakın olduğu için yüksek verimli bir ayırım sağlanamamıştır. $\mathrm{Bu}$ çalışmada, manyetik ayırma ile bir ön konsantrenin alınması sonrasinda flotasyon ile minerallerin birbirlerinden verimli bir şekilde ayrıldığı sonucuna ulaşılmıştır (Vaccarezza ve Anderson, 2018)

Rusya- Kola Peninsul'da bulunan Lovozero yatağında NTE minerali olarak esas mineral loparit tespit edilmiş ve üretimi yapılmaktadır. 1934 yılında keşfedilen yatak 1951 yılında işletilmeye başlanmıştır. \%95 içerikli Loparit konsantresi gravite ve elektrostatik ayırma yöntemleri ile elde edilirken yan ürün olarak \%96-98 argirine, \%20.7 nefelin ve \%31.7 feldspat konsantresi üretilmiştir. Bununla birlikte yapıda bulunan Ödalit minerali ile ilgili de çalışmalar yürütülmüştür (Hedrick vd., 1997).
Uygulanan flotasyon deneylerinde Na-oleat ve oleik asit toplayıcı olarak kullanılmıștır. \%13.5 $\mathrm{ZrO}_{2}$ ve \%2.5 NTE bulunduran yatakta, yağ asitleri ile ters flotasyon uygulanarak egirin minerali yüzdürülmüş̧ür (Vaccarezza ve Anderson, 2018).

Kanada- Nechalacho yatağından alınan örnek üzerinde yapılan çalışmada, Jordan ve ekibi flotasyon öncesi ön konsantre elde etmek için numuneyi 40 mikron altına ögüttükten sonra kademeli santrifüjlü ayırıcı kullanmıştır. Elde edilen kosantreler düşük alan şiddetli manyetik ayırıcı ve yüksek alan şiddetli manyetik ayırıcıda, manyetik ve manyetik olmayan ürünler elde edilmiştir. Elde edilen ürünlere karakterizasyon işlemleri gerçekleştirilerek ürünlerdeki mineraller tespit edilmiştir. XRD sonuçlarına göre NTE minerali olarak allanit ve basnazit pik vermiştir. Şekil 5'de yapılan deneylerin derlendiği proses akım șemasına ve NTO, demiroksitler ve silikat içeriklerine yer verilmektedir (Jordans vd., 2016).

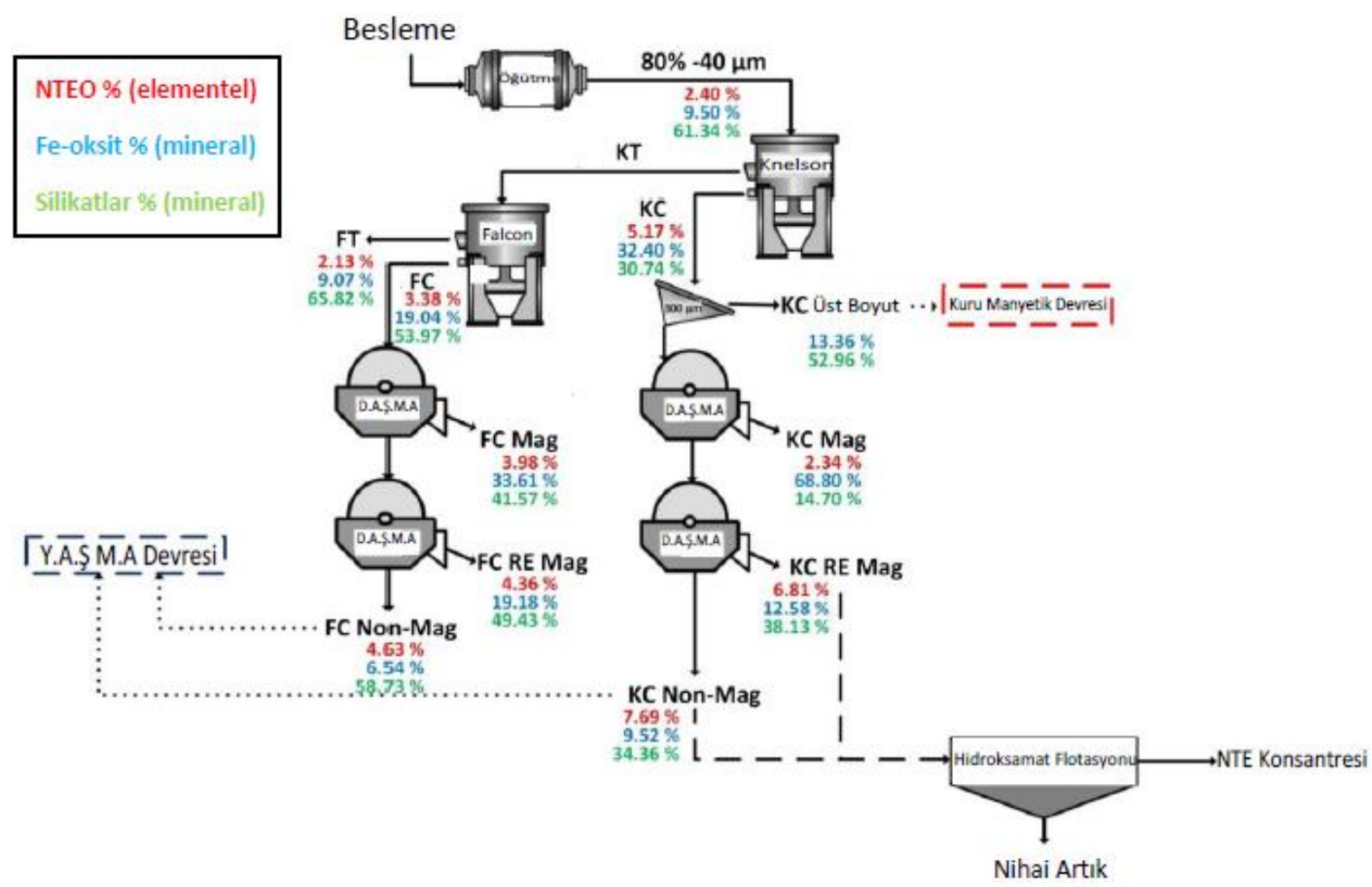

Şekil 5. Kanada-Nechalacho yatağından alınan örnek üzerine geliştirilen akım şeması (Jordens vd., 2016)

$\mathrm{Nb}$ yataklarında oluşum gösteren Piroklor $\left[(\mathrm{Na}, \mathrm{Ca})_{2} \mathrm{Nb}_{2} \mathrm{O}_{6}(\mathrm{OH}, \mathrm{F})\right], \mathrm{Nb}$ rezervlerinin \%95'inde bulunmaktadır. Dünyadaki en büyük $\mathrm{Nb}$ madenleri
Brezilya (Araxa ve Catalao) ve Kanada'da (SaintHonoré) bulunmaktadır. Bu yataklarda yapılan zenginleştirme çalışmalarında $\mathrm{Nb}$, katyonik 
toplayıc1larla kademeli olarak flotasyon ile zenginleştirilmektedir. Katyonik kollektörün aynı zamanda metal kayıplarına da yol açması sebebiyle ön zenginleştirme olarak birçok adım gerçekleștirilmiștir. Manyetik ayırma, şlam giderimi, ters karbonat flotasyonu, manyetik ayırma ve piroklor flotasyonu gibi denemeler mevcuttur. Niobec

\section{GENEL DEĞERLENDİRME}

Sahip olduğu birçok karakteristik özellikleri ile NTE, savunma sanayii ve yüksek teknoloji gerektiren malzemeler gibi stratejik alanlarda kullanım alanı bulmaktadırlar. Rezerv dağılımı ve üretim durumu göz önünde bulundurulduğunda Çin'in tekel konumunda olduğu ve ihracata yönelik kısitlamalar getirdiği bilinmektedir. Dünyadaki üretimin yaklaşık \%90'1 bastnazit, monazit ve ksenotim minerallerinden sağlanmaktadır. Avrupa gibi NTE kaynakları kısıtlı olan ve yüksek teknoloji üreten ülkeler bu sorunu çözmek için ikincil NTE mineralleri ve e-atık, maden artıkları, uçucu küller gibi artıklardan kazanıma yönelmişlerdir.

NTE konsantre üretiminde yan kayaçlar, tane serbestleşme boyutu ve mineral özelliklerinin farklılık göstermesi sebebiyle aynı yatak türlerinde bile zenginleștirme yöntemleri ve proses akım şemaları çeșitlilik gösterebilmektedir.

Son zamanlarda, Ülkemizde de NTE'lerin değerlendirilmesine yönelik çalışmalar oldukça yoğunlaşmıș durumdadır. Gerek kurumlar ve gerekse de araştırma grupları bu konu üzerinde yoğun araştırmaları sürdürmektedir.

$\mathrm{Bu}$ kapsamda; Türkiye Enerji, Nükleer ve Maden Araştırma Kurumu (TENMAK) 28 Mart 2020 tarihli ve 31082 sayıl resmi gazetede yayımlanan Cumhurbaşkanlığı Kararnamesi ile enerji, maden, iyonlaştırıcı radyasyon, parçacık hızlandırıcıları ve nükleer teknoloji alanında hizmet etmek, Türkiye'nin rekabet gücünü artırmak ve sürekli kılmak, inovasyon ihtiyacını karșılamak, yeni ürünlerin üretimini ve var olanların geliştirilmesini sağlamak, araştırmacılara bilimsel ortam temin etmek, kamu ve özel hukuk kișileriyle iș birliği içinde bilimsel araştırmalar yapmak, yaptırmak, bu araştırmaları koordine etmek, teşvik etmek, araştırma ve geliştirme faaliyetlerine katkı sağlamak, bilimsel, teknik ve idari çalışmaları yapmak, yaptırmak, düzenlemek, desteklemek, iş birlikleri kurmak ve koordine etmek amaciyla kurulmuştur. madeninde katyonik kollektörle kazanımda piroklorun \%15'inin kaybedildiği bildirilmiştir. Pirokloru yüzdürmek için hidroksamik asit ve sodyum oleat alternatifleri denenen bir çalışmada hidroksamik asitin ince boyutlarda daha yüksek verim sağladığı sonucuna varılmıştır (Liu vd., 2019)

$\mathrm{Bu}$ derleme çalışması kapsamında güncel kaynaklardan bir literatür taraması yapılmıs, Dünya'daki birincil ve ikincil NTE minerallerinden örnekler sunularak prosesler incelenmiştir. Özellikle kaynak arayışında olan ülkelerin şu an ticari avantajı daha düşük olan ikincil minerallerden NTE kazanımları ile ilgili yaptıkları çalışmalar gelecekte kaynakların azalması ile birlikte daha da önem kazanacaktır.

\section{ÇIKAR ÇATIŞMASI BEYANI}

Yazar/ Yazarlar bu makale ile ilgili herhangi bir çıkar çatışması bildirmemektedir.

\section{ARAŞTIRMA VE YAYIN ETİĞİ BEYANI}

Yazar/Yazarlar bu çalışmanın araştırma ve yayın etiğine uygun olduğunu beyan eder.

\section{KAYNAKLAR}

Abaka-Wood, G., Addai-Mensah, J. ve Skinner, W. (2016). Review of flotation and physical separation of rare earth element minerals. $4^{\text {th }}$ UMaT Biennial International Mining and Mineral Conference, pp. 5562, Tarkwa.

Anderson, C. D., Taylor, P. R. ve Anderson, C. G. (2016). Rare earth flotation fundamentals: A review. IMPC 2016: XXVIII International Mineral Processing Congress Proceedings, pp. 1-15, Quebec. Canadian Institute of Mining, Metallurgy and Petroleum.

Balaram, V. (2019). Rare earth elements: A review of applications, occurrence, exploration, analysis, recycling, and environmental impact, Geoscience Frontiers, 10, 1285-1303.

Bulatovic, S. M. (2010). Flotation of REO Minerals. Handbook of Flotation Reagents: Chemistry, Theory and Practice, 151-173. doi:10.1016/b978-0-44453082-0.00024-X

Campbell, G. A. (2014). Rare earth metals: A strategic concern. Miner Econ, 27, 21-31. doi:10.1007/s13563014-0043-y

Chen, W., Honghui, H., Bai, T. ve Jiang, S. (2017). Geochemistry of monazite within carbonatite related REE deposits, Resources. 
Costis, S., Mueller, K. K., Coudert, L., Neculita, C. M., Reynier, N. ve Blais, J.-F. (2021). Recovery potential of rare earth elements from mining and industrial residues: A review and cases studies, Journal of Geochemical Exploration.

Dostal, J. (2017). Rare earth element deposits of alkaline igneous rocks. Resources.

Dushyanthaa, N., Batapolaa, N., Ilankoonb, I., Rohithaa, S., Premasiria, R., Abeysinghea, B. ve Dissanayakea, K. (2020). The story of rare earth elements (Rees): Occurrences, global Distribution, genesis, geology, mineralogy and global production, Ore Geology Reviews, 122, 1-17.

Faris, N., Ram, R., Tardio, J., Bhargava, S., McMaster, S. ve Pownceby, M. I. (2017). Application of ferrous pyrometallurgy to the beneficiation of rare earth bearing iron ores - A review. Minerals Engineering, 110, 20-30.

Goodenough, K. M., Wall, F. ve Merriman, D. (2018). The rare earth elements: Demand, global resources, and challenges for resourcing future generations. Natural Resources Research, 27, 201-216.

Gupta, C. K. ve Krishnamurthy, N. (2005). Extractive metallurgy of rare earths. CRC Press.

Hao, C. ve Corby, A. G. (2017). Alternative flowsheet for rare earth beneficiation of bear lodge ore. Minerals Engineering, $\quad 110, \quad 166-178$ doi:10.1016/j.mineng.2017.04.016

Haque, N., Hughes, A., Lim, S. ve Vernon, C. (2014). Rare earth elements: Overview of mining, mineralogy, uses, sustainability and environmental impact. Resources, 614-635. doi:10.3390/resources3040614

Hedrick, J. B., Sinha, S. P. ve Kosynkin, V. D. (1997). Loparite, A rare-earth ore $(\mathrm{Ce}, \mathrm{Na}, \mathrm{Sr}, \mathrm{Ca})(\mathrm{Ti}, \mathrm{Nb}, \mathrm{Ta}$, $\mathrm{Fe}) \mathrm{O}_{3}$, Journal of Alloys and Compounds, 250, 467470.

Jordens, A., Cheng, Y. P. ve Waters, K. E. (2013). A review of the beneficiation of rare earth element bearing minerals. Minerals Engineering, 4, 97-114.

Jordens, A., Christopher M., Grammatikopoulos, T., Hart, B. ve Waters, K. E. (2016). Beneficiation of the nechalacho rare earth deposit: Flotation response using benzohydroxamic acid. Minerals Engineering, 99, 158-169.

Jyothi, R. K., Thenepalli, T., Ahn, J. W., Parhi, P. K., Chung, K. W. ve Lee, J.-Y. (2020). Review of rare earth elements recovery from secondary resources for clean energy technologies: Grand opportunities to create wealth from waste. Journal of Cleaner Production.

Kumari, A., Panda, R., Jha, M. K., Kumar, J. R. ve Lee, J. Y. (2015). Process development to recover rare earth metals from monazite mineral: A review. Minerals Engineering, 79, 102-115.

Kurşun, İ., Terzi, M. ve Özdemir, O. (2019). Determination of surface chemistry and flotation properties of rare earth mineral: Allanite. Minerals Engineering, 132, 113-120.

Li, L. Z. ve Yang, X. (2014). China's rare earth ore deposits and beneficiation. ERES 2014: 1st European Rare Earth Resources Conference, pp: 26-36, Milos.

Liu, M., Li, H., Jiang, T. ve Liu, Q. (2019). Flotation of coarse and fine pyrochlore using octyl hydroxamic acid and sodium oleate. Minerals Engineering, 132, 191-201.

Lynas Rare Earth. (t.y.). Retrieved from https://lynasrareearths.com/about-us/locations/mtweld-western-australia/

Mancheri, N. A. (2015). World trade in rare earths, Chinese export restrictions, and implications. Resources Policy, 46, 262-271. doi:10.1016/j.resourpol.2015.10.009

Moustafa, M. I. ve Abdelfattah, N. A. (2010). Physical and chemical beneficiation of the Egyptian beach monazit. Resource Geology, 60, 288-299.

Schüler, D., Buchert, M., Liu, R., Dittrich, S. ve Merz, C. (2011). Study on rare earths and their recycling. Darmstadt: Öko-Institut e.V.

Suli, L. M., Ibrahim, W. H., Aziz, B. A., Deraman, M. R. ve Ismail, N. A. (2017). A review of rare earth mineral processing technology, Chemical Engineering Research Bulletin, 19, 20-35. Erişim adresi: https://doi.org/10.3329/cerb.v19i0.33773

Terzi, M. (2017). Isparta Yöresi nadir toprak elementlerinin kazanımı için yeni proseslerin geliştirilmesi (Doktora Tezi). Yöktez Erişim No: 483710, İstanbul: İstanbul Üniversitesi.

U.S. Geological Survey, 2021. Mineral Commodity Summaries 2021. U.S. Geological Survey, Reston, Virginia.

Vaccarezza, V. ve Anderson, C. (2018). Beneficiation and leaching study of Norra Kärr ödalit mineral. In H. K. al., Rare Metal Technology, The Minerals, Metals \& Materials Society.

Wall, F. (2014). 13. Rare earth elements. Gunn,G. (Der). Critical metals handbook, pp. 312-340.

Yang, X., Satur, J. V., Sanematsu, K., Laukkanen, J. ve Saastamoinen, T. (2015). Beneficiation studies of a complex REE ore. Minerals Engineering, 71, 55-64.

Yıldiz, N. (2016). Nadir toprak elementleri. Ankara.

Zhang, Y. (2016). Froth flotation of xenotime. (YL Tezi). Colorado School of Mines, Arthur Lakes Library. Erişim adresi: http://hdl.handle.net/11124/170057

Zhang, W., Noble, A., Yang, X. ve Honaker, R. (2020). A comprehensive review of rare earth elements recovery from coal-related materials. Minerals. doi: $10.3390 / \min 10050451$ 